\title{
Granulomatose com poliangeíte: evolução atípica com acometimento peritoneal
}

\section{Granulomatosis with polyangeitis: atypical evolution with peritoneal involvement}

\author{
Giovanni Graziano de Sousa Xavier ${ }^{1}$ Ricardo Coelho Reis². \\ 1 Hospital Universitário Walter Cantídio (HUWC), Universidade Federal do Ceará (UFC), Fortaleza, Ceará, Brasil. 2 Universidade \\ Federal do Ceará (UFC), Empresa Brasileira de Serviços Hospitalares (EBSERH), Fortaleza, Ceará, Brasil.
}

\section{RESUMO}

A Granulomatose com poliangeíte (GPA) trata-se de uma vasculite de pequenos vasos, que cursa com acometimento inflamatório vascular imunologicamente mediado, determinando dano estrutural e funcional à parede dos vasos. A doença atinge predominantemente as vias aéreas superiores, inferiores e os rins, podendo levar a formações granulomatosas, vasculite e necrose desses órgãos. Apresentações clínicas com acometimento dermatológico, neurológico, genitourinário, e gastrointestinal são atípicas e podem representar um desafio diagnóstico para o clínico. Relatamos um caso de um paciente de 26 anos, que teve diagnóstico de Granulomatose com poliangeíte, apresentando no início do seu curso clínico um acometimento do trato gastrointestinal de forma isolada, com comprometimento de outros órgãos, posteriormente, na sua evolução clínica. O acometimento gastrointestinal rotineiramente ocorre nos primeiros dois anos de evolução da doença e pode ser o primeiro achado da GPA, precedendo manifestações clínicas mais frequentes da doença, o que pode dificultar o diagnóstico precoce.

Palavras-chave: Granulomatose com poliangeíte. Abdome agudo. Rituximab. Estenose traqueal.

\section{ABSTRACT}

Granulomatosis with polyangeitis (GPA) is a vasculitis of small vessels, which presents with immunologically mediated vascular inflammatory involvement, determining structural and functional damage to the vessel wall. The disease predominantly affects the upper and lower airways and the kidneys, which can lead to granulomatous formations, vasculitis and necrosis of these organs. Clinical presentations with dermatological, neurological, genitourinary, and gastrointestinal involvement are atypical and may represent a diagnostic challenge for the clinician. We report a case of a 26-year-old patient diagnosed with Granulomatosis with polyangeitis, presenting at the beginning of his clinical course an involvement of the gastrointestinal tract in isolation, with involvement of other organs, later on in his clinical evolution. Gastrointestinal involvement routinely occurs within the first two years of disease progression and may be the first finding of Granulomatosis with polyangeitis, preceding more frequent clinical manifestations of the disease, which may hinder early diagnosis.

Keywords: Granulomatosis with polyangiitis. Acute abdomen. Rituximab. Tracheal stenosis.

Autor correspondente: Giovanni Graziano de Sousa Xavier, Rua Sigefredo Pinheiro, 545, Fátima, Fortaleza, Ceará. CEP: 60415160 . Telefone: +55 88 99991-2030. E-mail: giovannigsxavier@gmail.com

Conflito de interesses: Não há qualquer conflito de interesses por parte de qualquer um dos autores.

Recebido em: 28 Nov 2018; Revisado em: 26 Jun 2019; Aceito em: 11 Jul 2019. 


\section{INTRODUÇÃO}

A Granulomatose com poliangeíte (GPA), até pouco tempo denominada Granulomatose de Wegener, trata-se de uma vasculite de pequenos vasos, que cursa com acometimento inflamatório vascular imunologicamente mediado, determinando dano estrutural e funcional à parede dos vasos. Com os primeiros casos descritos em 1930, a Granulomatose com poliangeíte é uma doença sistêmica idiopática rara, com prevalência de 3 casos a cada 100.000 pessoas, ${ }^{1-2}$ com pico de incidência por volta dos 50-60 anos..$^{3-4}$ Não apresenta predileção por sexo, e acomete de forma prioritária pessoas de raça branca. ${ }^{5}$

A sobrevida média dos casos não tratados é em torno de 5 meses, com $82 \%$ dos pacientes evoluindo com óbito em 1 ano e mais de $90 \%$ em dois anos. ${ }^{1} \mathrm{~A}$ introdução de uma terapia agressiva nos últimos anos, com imunossupressores, proporcionou melhora do prognóstico. Com um tratamento adequado a sobrevida média em 10 anos é em torno de $40 \%{ }^{6}$

A doença atinge de forma predominante as vias aéreas superiores, inferiores e os rins, podendo levar à formação granulomatosa, vasculite e necrose desses órgãos. Apresentações clínicas com acometimento dermatológico, neurológico, genitourinário, e gastrointestinal são atípicas e podem representar um desafio diagnóstico para o clínico. Diagnósticos definidos de forma tardia, já com a doença avançada e com complicações graves, ocorrem de forma frequente na Granulomatose com poliangeíte (GPA), sobretudo nos casos que se apresentam de forma atípica inicialmente. ${ }^{7}$

\section{RELATO DO CASO}

Paciente, 26 anos, pardo, solteiro, natural e procedente de Sobral, Ceará, e desempregado. Encaminhado ao Serviço de Pneumologia do Hospital Universitário Walter Cantídio para investigação diagnóstica de um quadro de evolução prolongada, que havia se iniciado há cerca de 5 anos, quando ele foi submetido a apendicectomia, tendo, após 15 dias da primeira abordagem cirúrgica, apresentado quadro de dor abdominal, náuseas, vômitos, astenia, com necessidade de laparotomia exploradora, onde foi coletado material de região peritoneal com sinais de fibrose local. O histopatológico do material coletado revelou presença de granulomas não-caseosos em tecido peritoneal, sendo então realizado tratamento padrão para tuberculose peritoneal pela equipe assistente do hospital local.

Após um ano, passou a apresentar dispneia aos médios esforços tendo sido constatada estenose de vias aéreas em região subglótica, com necessidade de realização de traqueoplastia. O histopatológico de segmento traqueal mostrou sinais de traqueíte crônica e inespecífica, associada à marcada fibrose local.

Há cerca de 1 ano, procurou atendimento médico ambulatorial queixando-se de adinamia, comprometimento do estado geral, hiporexia e náuseas, tendo sido diagnosticado insuficiência renal crônica, sem etiologia definida, com necessidade de terapia dialítica.
$\mathrm{Na}$ evolução clínica atual, o paciente apresentava quadro de tosse com expectoração mucoide persistente, diária e progressiva, com evolução de 18 meses. Referindo também presença de hemoptise leve de caráter esporádico. Informava que o quadro se acentuou há cerca de 8 meses, quando passou a apresentar piora da hemoptise, febre vespertina quase diária, astenia, dispneia aos moderados esforços e perda ponderal de cerca de $24 \mathrm{~kg}$.

Tomografia computadorizada de alta resolução (TCAR) de tórax realizada em 2016, demonstrou a presença de pequena cavitação no segmento lateral do lobo médio pulmonar com presença do "sinal do halo". Nessa época, a pesquisa de BAAR (bacilo álcool ácido resistente) no escarro foi negativa, bem como as pesquisas e culturas do lavado broncoalveolar (LBA) para fungos, germes piogênicos, e bacilo de Koch (BK). A dosagem de galactomananas do LBA também foi negativa. Durante a admissão realizou nova tomografia que mostrou opacidades com atenuação em vidro fosco, predominantes em região peribrônquica, associada a discretas bronquiectasias de tração no lobo médio, sem visualização de qualquer processo cavitário. A broncoscopia demonstrou a presença de um processo cicatricial pós-traqueoplastia, associada a secreção sanguinolenta difusa em toda árvore brônquica, com culturas negativas para germes piogênicos, BK e fungos, bem como citologia oncótica negativa. A dosagem de complemento sérico mostrou-se normal. A velocidade de hemossedimentação (VHS) mostrouse elevada e o P-ANCA foi reagente com uma titulação de 1:40. As sorologias para vírus $\mathrm{B}, \mathrm{C}$ e retrovírus foram negativas. A biópsia transtorácica de lobo médio pulmonar revelou extensa hemorragia intra-alveolar, além de fibrina intra-alveolar e capilarite representada por exsudação predominantemente neutrofílica em septos alveolares. Os achados histopatológicos associados ao quadro clínico-laboratorial foram compatíveis com Granulomatose com poliangeíte. Uma terapêutica específica com Rituximab foi iniciada, e o paciente apresentou uma boa resposta clínica com desaparecimento dos sintomas respiratórios e melhora do estado geral.

No mês de dezembro do mesmo ano, o paciente evoluiu com piora do estado geral, febre, tosse produtiva, dispneia, com necessidade de novo internamento hospitalar, onde cursou com insuficiência respiratória grave com necessidade de suporte de ventilação mecânica, culminando com óbito. Não foi realizada necropsia.

\section{DISCUSSÃO}

As manifestações clínicas prodrômicas da GPA cursam com fadiga, astenia, inapetência, emagrecimento e perda ponderal. Esse quadro clínico pode durar semanas a meses sem manifestações clínicas específicas. O comprometimento intestinal da GPA ocorre em cerca de 4-10 \% dos pacientes, podendo cursar com dor abdominal, náuseas, vômitos, diarreia, hematêmese, melena e perfuração intestinal, sendo esta última uma das manifestações mais frequentes. ${ }^{8} \mathrm{~A}$ vasculite pode provocar alterações patológicas locais ou difusas no trato gastrointestinal. A variedade de lesões pode 
se apresentar como úlcera ou edema de mucosa, hemorragia intestinal, paralisia ileal, isquemia mesentérica, obstrução ou perfuração intestinal. $\mathrm{O}$ acometimento gastrointestinal rotineiramente ocorre nos primeiros dois anos de evolução da doença e pode ser o primeiro achado da GPA, precedendo manifestações clínicas mais características da doença, o que pode trazer dificuldade no diagnóstico precoce, ${ }^{9}$ como no caso em questão. O diagnóstico histopatológico por via endoscópica apresenta baixa sensibilidade tendo em vista a coleta de material de mucosa superficial, o que dificulta a análise de vasculite de pequenos e médios vasos intestinais. A biópsia cirúrgica apresenta maior valor diagnóstico. Doença de Chron e tuberculose intestinal cursam como os principais diagnósticos diferenciais. Ainda hoje, há controvérsias acerca do acometimento intestinal na GPA. Alguns autores sugerem que o acometimento gastrointestinal poderia ser induzido pelo uso prévio de corticoterapia sistêmica. ${ }^{10} \mathrm{O}$ paciente citado apresentou, no início da sua história clínica, um quadro de abdome agudo com necessidade de cirurgia, que demonstrou no histopatológico peritoneal a presença de granulomas nãocaseosos, um dos achados da GPA. A falta de outros dados clínicos associados no início do quadro dificultou a definição diagnóstica precoce, que só foi possível após 5 anos de evolução da doença.

O acometimento pulmonar ocorre em até 90\% dos casos e pode ser caracterizado pela presença de tosse produtiva, dispneia, hemoptise, sibilância, estridor e dor torácica. Essas manifestações podem ser acompanhadas de achados de estenose traqueal ou subglótica. No caso citado, o paciente cursou com estenose traqueal, o que, a posteriori, levou a equipe assistencial a aventar a hipótese diagnóstica de GPA. O paciente também apresentou tosse persistente com secreção mucoide e hemoptóicos, o que está diretamente relacionado com a ocorrência de vasculite de pequenas artérias do parênquima pulmonar.

O acometimento renal é o responsável pela maioria das mortes na GPA e ocorre predominantemente de forma tardia, podendo cursar com gromulonefrite focal e segmentar com proteinúria e hematúria ou evoluir para glomerulonefrite rapidamente progressiva e estágio renal terminal. A falência renal precoce ou ao diagnóstico da doença é marcador de mau prognóstico. No caso em questão, o paciente apresentou insuficiência renal com necessidade de diálise após cerca de 4 anos do início

\section{REFERÊNCIAS}

1. Hartl DM, Aidan P, Brugière O, Sterkers O. Wegener's granulomatosis presenting as a recurrence of chronic otitis media. Am J Otol. 1998;19(1):54-60.

2. Koldingsnes W, Nossent H. Epidemiology of Wegener's granulomatosis in nothern Norway. Art Rheum. 2000;43(11):2481-7.

3. Jennette JC, Falk RJ. Small-vessel vasculitis. N Engl J Med. 1997;337:1512.

4. Seo P, Stone JH. The antineutrophil cytoplasmic antibodyassociated vasculitides. Am J Med. 2004;117:39. do quadro, quando ainda não apresentava um diagnóstico etiológico. Hematúria, leucocitúria, elevação de ureia e creatinina são achados laboratórios frequentes no paciente com Granulomatose com poliangeíte.

O diagnóstico de GPA é sugerido com a associação dos achados clínicos, laboratoriais, histopatológicos e a presença do anticorpo anticitoplasma de neutrófilos (ANCA), com cerca de $80 \%$ dos casos direcionados contra a antiproteinase $3(\mathrm{C}-\mathrm{ANCA})^{11}$. A baixa prevalência da doença e a apresentação clínica variável, muitas vezes semelhante a inúmeras outras condições clínicas no início do quadro, acabam retardando o diagnóstico, o que contribui para um pior desfecho. Doenças do tecido conjuntivo, neoplasias, infecções, e doenças granulomatosas estão entre os principais diagnósticos diferenciais. A tuberculose muitas vezes pode apresentar-se de forma semelhante ${ }^{12}$ e pela prevalência em nosso país, pode ser um elemento confundidor, mesmo quando o granuloma não se apresenta caseoso, como no caso em questão.

A taxa de mortalidade da GPA tem reduzido ao longo dos últimos anos em decorrência do surgimento de inúmeras alternativas terapêuticas. ${ }^{6}$ Vasculite ativa, doença cardiovascular, malignidades e principalmente infecções secundárias estão entre os principais fatores contribuintes para a mortalidade. ${ }^{12}$

O tratamento da Granulomatose com poliangeíte envolve um esquema de medicações imunossupressoras direcionadas para cada paciente de acordo com a gravidade da doença, progressão dos sintomas e resposta terapêutica. Ciclofosfamida, glicocorticoide e Rituximab são as principais opções para indução da remissão da doença. O Rituximab, anticorpo anticlonal anti-Cd 20, é um agente potente no tratamento, especialmente recomendado nas formas recidivantes e refratárias a outras formas de tratamento. ${ }^{12}$ Outros agentes utilizados como alternativas incluem a azatioprina, leflunomida, metotrexato e micofenolato de mofetila. ${ }^{13}$

Este caso demonstra a importância de considerar o diagnóstico de vasculite em pacientes com doenças sistêmicas de curso prolongado. A apresentação clínica da Granulomatose com poliangeíte pode mostrar-se extremamente variável a depender do órgão que foi acometido. No caso relatado, o diagnóstico não foi definido de forma precoce, tendo em vista a apresentação inicial atípica com acometimento do trato gastrointestinal.
5. Falk RJ, Hogan S, Carey TS, Jennette JC. Clinical course of antineutrophil cytoplasmic autoantibody-associated glomerulonephritis and systemic vasculitis. The Glomerular Disease Collaborative Network. Ann Intern Med. 1990;113(9):656-63.

6. Aasarød K, Iversen BM, Hammerstrøm J, Bostad L, Vatten L, Jørstad S. Wegener's granulomatosis: clinical course in 108 patients with renal involvement. Nephrol Dial Transplant. 2000; $15: 611-8$

7. Blundell AG, Roe S. Wegener granulomatosis presenting asa pleural effusion. BMJ. 2003;327:95-6. 
8. Pagnoux C, Mahr A, Cohen P, Guillevin L. Presentation and outcome of gastrointestinal involvement in systemic necrotizing vasculitides: analysis of 62 patients with polyarteritis nodosa, microscopic Polyangiitis, Wegener granulomatosis, Churg-Strauss syndrome or rheumatoid arthritis-associated vasculitis. Medicine (Baltimore). 2005;84(2):115-28.

9. Masiak A, Zdrojewski Ł, Zdrojewski Z, Bułło-Piontecka B, Rutkowski B. Gastrointestinal tract involvement in granulomatosis with polyangiitis. Prz Gastroenterol. 2016;11(4):270-5.

10. Akça T, Çolak T, Çaðlýkülekçi M, Öcal K, Aydýn S. Intestinal perforation in Wegener's granulomatosis: a case report. Ulus Travma Derg. 2005;11:348-51.
11. Lorenzet IC, Carpena AB, C Stapassoli Filho, Tubone TQ, Bohlke M. Granulomatose de Wegener: apresentação atípica com hemorragia digestiva baixa. J Bras Nefrol. 2004;26(3):170-4.

12. Grygiel-Górniak B, Limphaibool N, Perkowska K, Puszczewicz M. Clinical manifestations of granulomatosis with polyangiitis: key considerations and major features. Postgrad Med. 2018;130(7):58196.

13. Antoniu SA. Treatment options for refractory Wegener's granulomatosis: a role for rituximab? Curr Opin Investig Drugs. 2007;8:927-32.

\section{Como citar:}

Xavier GG, Reis RC. Granulomatose com poliangeíte: evolução atípica com acometimento peritoneal. Rev Med UFC. 2020 jan-mar;60(1):47-50. 